Jurnal Widya Sastra Pendidikan Agama Hindu, Vol 4, No. 2, 2022

ISSN: 2656-7466

\title{
SAMPI GERUMBUNGAN, Seni Budaya Khas Buleleng
}

\author{
Dewa Nyoman Sucita \\ STKIP Agama Hindu Singaraja \\ Email: sucitadewa8@gmail.com
}

\begin{abstract}
ABSTRAK
Tujuan yang ingin diperoleh dari penelitian ini pada dasarnya untuk dapat mengungkap keberadaan Sampi Gerumbungan yang berada di desa Kaliasem Kabupaten Buleleng. Untuk mencapai tujuan tersebut digunakan beberapa metode, antara lain: dalam menentukan informan digunakan teknik purposive sampling dan snowball sampling; mengumpulkan data digunakan teknik wawancara terstrktur dan pencatatan dokumen; dan dalam menganalisis data digunakan metode analisis data kualitatis dengan tiga tahap, yaitu menreduksi data, mendisplay data dan menarik simpulan dan verifikasi. Berdasarkan langkah-langkah tersebut, maka hasil penelitian yang diperoleh, sebagai berikut: (1) asal-usul berkembangnya seni budaya Sampi Gerumbungan di desa Kaliasem berawal dari hasil kreativitas para petani setelah mereka panen raya. Hal ini dilakukan oleh petani diperkirakan mulai tahun 1923. Dan dalam perkembangan berikutnya pementasan Sampi Gerumbungan ini tidak saja terkait dengan pertanian melainkan berimbas pula pada bidang parawisata, karena dimanfaatkan oleh pemerintah Buleleng sebagai salah satu paket wisata di Buleleng, sehingga sampai saat ini ada kelompok-kelompok Sampi Gerumungan di Buleleng. (2) Nilai-nilai yang terkandung dalam seni budaya Sampi Gerumbungan, antara lain: a. nilia seni/keindahan, b. nilai budaya, c. nilai sacral dan d. nilai ekonomis. (3) Peralatan yang digunakan dalam Sampi Gerumbungan, antara lain: a. Uga; b. Samped, c. Kunali, d. Lampit, e. Tali Tengen, f. daun lampit, g. pelayah, h. Gelang Gongseng, i. Gerumbungan, j. Pecut dan k. Pengatik. (4) Keberadaan sampi Gerumbungan dewasa ini mengalami perubahan dan peningkatan kualitas dilihat dari tempat pelaksanaannya, waktu pelaksanaannya, Kostum yang digunakan pada saat pementasan, kreteria pementasan dan para penikmatnya.
\end{abstract}

Kata kunci: Sampi Gerumbungan 
Jurnal Widya Sastra Pendidikan Agama Hindu, Vol 4, No. 2, 2022

ISSN: 2656-7466

\title{
SAMPI GERUMBUNGAN, Seni Budaya Khas Buleleng
}

\author{
Oleh \\ Dewa Nyoman Sucita \\ STKIP Agama Hindu Singaraja \\ Email:sucitadewa8@gmail.com
}

\section{ABSTRACT}

The objective of this research is basically to reveal the existence of Sampi Gerumbungan in Kaliasem village, Buleleng Regency. To achieve this goal, several methods were used, including: in determining the informants, purposive sampling and snowball sampling were used; collect data using structured interview techniques and document recording; and in analyzing the data used qualitative data analysis method with three stages, namely reducing data, displaying data and drawing conclusions and verification. Based on these steps, the results of the research obtained are as follows: (1) the origin of the development of the Sampi Gerumbungan art and culture in the village of Kaliasem stems from the creativity of the farmers after they harvest. This was done by farmers, it is estimated that starting in 1923. And in subsequent developments the Sampi Gerumbungan performance is not only related to agriculture but also has an impact on the tourism sector, because it is used by the Buleleng government as one of the tour packages in Buleleng. the Sampi Gerumungan group in Buleleng. (2) The values contained in the Sampir Gerumbungan art and culture include: a. the value of art/beauty, b. cultural values, c. sacred value and d. economic value. (3) The equipment used in Sampi Gerumbungan, among others: a. Uga; b. Samped, c. Kunali, d. Lampit, e. Tali Tengen, f. leaf lampit, g. waiter, h. Gongseng Bracelet, i. Grub, j. Whip and k. tamper. (4) The existence of Sampi Gerumbungan has changed and improved in quality, seen from the place where it is performed, when it is performed, the costumes used during the performance, the performance criteria and the audience.

Key word: Sampi Gerumbungan 
Jurnal Widya Sastra Pendidikan Agama Hindu, Vol 4, No. 2, 2022

ISSN: 2656-7466

\section{PENDAHULUAN}

Sebuah seni budaya yang dapat dilahirkan oleh manusia pada umumnya terkait dengan kehidupan, profesi dan kondisi wilayah di mana seni budaya itu tercipta. Sebagai contoh di Indonesia, termasuk Bali, di mana masyarakatnya tergolong masyarakat yang agraris, karena penduduknya atau masyarakatnya sebagian besar hidup dari bertani, sehingga banyak kita jumpai lahirnya seni budaya yang berawal dan berkaitan dengan pekerjaan masyarakatnya sebagai petani. Misalnya, tari Genggong di desa Batuan, Kecamatan Sukawati, Gianyar tercipta berlatarbelakangkan dari kegiatan petani setelah panen raya. Para petani bersuka ria di sawah karena hasil taninya berhasil dengan baik, sehingga akhirnya dari permainan yang sederhana ini terciptalah tari Genggong. Budaya seni Genjek di Kabupaten Karangasem diperkirakan pula tercipta terkait dengan keberhasilan para petani di sawah dengan mengadakan hiburan disertai pesta minum tuak yang banyak dihasilkan di daerah ini, sehingga dari aktivitas masyarakat tani ini lahirnya Seni Budaya Genjek ini. Demikian pula dengan budaya seni Makepung di Jembrana dan Karapan Sapi yang ada di Madura, yang pada dasarnya tidak dapat dipisahkan dengan kehidupan masyarakat petani di daerahnya masing-masing.

Terkait dengan uraian di atas, di Kabupaten Buleleng tepatnya di desa Kaliasem, Kecamatan Banjar terdapat seni budaya sejenis Karapan Sapi di Madura dan Makepung di Kabupaten Jembrana, yang disebut Sampi Gerumbungan. Seni budaya Sampi Gerumbungan ini tercipta pula terkait dengan kehidupan petani masyarakatnya. Budaya Sampi Gerumbungan yang ada di desa Kaliasem ini tentu tidak sama dengan seni Makepung di Jembrana dan Karapan Sapi di Madura. Masingmasing daerah mempunyai ciri khas, sehingga antara satu daerah dengan daerah lainnya akan berbeda-beda walaupun dalam kategori yang sejenis.

Dalam hal ini yang dimaksud dengan Sampi Gerumbungan adalah sebuah seni yang menggunakan binatang sapi (sampi dalam Bahasa Indonesia disebut sapi); dengan menggunakan Gerumbungan atau keroncongan atau okokan di lehernya; gerumbungan/ keroncongan/okokan adalah alat bunyi-bunyian yang dibuat dari kayu yang dibentuk sedemikian rupa sehingga nampak indah dan mengeluarkan suara jika sapi berjalan/lari. Keberadaan Sampi Gerumbungan dewasa ini tidak saja dimanfaatkan oleh petani dalam kaitannya panen raya, melainkan sudah berkembang dan merambah bidang lain khususnya dalam bidang pariwisata padahal sebagian kecil yang memahami hal ikhwal tentang Sampi Gerumbungan ini seperti sejarah lahirnya Sampi Gerumbungan di Buleleng, nilai-nilai yang terkandung dalam seni budaya Sampi gerumbungan, peralatan yang digunakan dalam Sampi Gerumbungan dan lain-lain. Hal inilah yang mendorong budaya Sampi Gerumbungan ini diangkat menjadi obyek penelitian.

Berdasarkan uraian di atas diketahui bahwa ada berbagai hal yang berhubungan dengan keberadaan Sampi Gerumbungan yang perlu dikaji antara lain: (1) Bagaimanakah asal-usul dan perkembangan seni budaya Sampi Gerumbungan di desa Kaliasem Buleleng? (2) Nilai-nilai apakah yang terkandung dalam seni budaya Sampi Gerumbungan? (3) Peralatan apa saja yang digunakan dalam pementasan sebuah atraksi Sampi Gerumbungan? (4) Bagaimanakah keberadaan Sampi Gerumbungan setelah dimanfaatkan dalam bidang pariwisata di Kabupaten Buleleng?

Bertitik tolak dari kajian tersebut, maka yang menjadi tujuan penelitian ini adalah dapat mengungkap secara gamblang keberadaan Sampi Gerumbungan di desa Kaliasem, yang meliputi:

1. Untuk mengetahui asal-usul dan perkembangan seni budaya Sampi Gerumbungan di desa Kaliasem Buleleng 
Jurnal Widya Sastra Pendidikan Agama Hindu, Vol 4, No. 2, 2022

ISSN: 2656-7466

2. Untuk mengetahui nilai-nilai yang terkandung dalam seni budaya Sampi Gerumbungan.

3. Untuk mengetahui peralatan yang digunakan dalam pementasan Sampi Gerumbungan.

4. Untuk mengetahui keberadaan Sampi Gerumbungan dalam kaitannya dengan bidang pariwisata di Kabupaten Buleleng.

\section{METODE PENELITIAN}

Ada beberapa metode yang digunakan dalam menuntaskan penelitian ini, yaitu: metode penentuan informan, metode pengumpulan data dan metode analisis data. Dalam menentukan informan digunakan teknik purposive sampling dan snowball sampling. Teknik purposive sampling adalah teknik penentuan informan (sumber data) dengan cara pilih memilih dengan pertimbangan tertentu, misalnya orang tersebut yang dianggap paling tahu tentang obyek yang diteliti. Sedangkan snowball sampling adalah teknik penentuan informan (sumber data) yang jumlah semakin bertambah apabila dipandang perlu dan akan dihentikan apabila sudah dipandang cukup oleh peneliti. Terkait dengan hal ini, informan yang dipilih adalah tokoh-tokoh masyarakat desa Kaliasem, para ketua dan anggota kelompok Sampi Gerumbungan, para petani, tokoh agama dan para pelaku pariwisata di sekitar Desa kaliasem.

Ada dua teknik yang digunakan dalam mengumpulkan data, yaitu wawancara terstrktur dan pencatatan dokumen. Wawancara berstruktur dipilih dengan alasan peneliti akan tervokus pada data yang diperlukan pada data yang diperlukan dalam penelitian yang dilaksanakan, sehingga hal-hal itulah yang ditanyakan pada informan. Pencatatan dokumen digunakan sebagai pelengkap data yang diperoleh dari wawancara. Pencatatan yang dilakukan dalam penelitian ini baik pada saat wawancara maupun mencatat dari sumber-sumber tertulis yang ada baik berupa peraturan-peraturan tertulis, kitab-kitab yang terkait dengan Sampi Gerumbungan. Selanjutnya digunakan teknik triangulasi, yaitu menggabungkan dari berbagai teknik pengumpulan data dan sumber data yang telah ada. Teknik ini digunakan dengan alasan di samping dapat mengumpulkan data juga sekaligus dapat menguji kredibilitas data. Menggunakan teknik triangulasi dalam pengumpulan data akan memperoleh data yang lebih konsisten, tuntas, dan pasti, serta akan lebih meningkatkan kekuatan data (Sugiyono, 2007:241).

Untuk dapat merumuskan hasil penelitian, maka data yang didapat harus dianalisis dengan metode analisis data. Dalam menganalisis data digunakan metode analisis data kualitatis dengan tiga tahap, yaitu menreduksi data, mendisplay data dan menarik simpulan dan verifikasi.

a. Reduksi Data

Data yang diperoleh berupa diskrepsi dirangkum, dipilih hal-hal yang pokok atau hal-hal berkaitan dengan masalah yang diteliti. Data yang telah direduksi akan memberikan gambaran yang lebih tajam dari hasil wawancara dan pengamatan yang telah dilaksanakan.

b. Display Data

Data yang didapat dalam pengumpulan data tentu jumlah sangat banyak, sehingga ada tata yang tidak sesuai dengan data yang dibutuhkan, sehingga ada yang harus dibuang atau disihkan. Dengan menyisihkan data yang tidak diperlukan akan memudahkan menarik simpulan. Hal ini dapat dilakukan dengan membuat model atau grafik sehingga keseluruhan data dan bagian-bagian dapat dipetakan dengan jelas.

c. Kesimpulan dan Verifikasi 
Jurnal Widya Sastra Pendidikan Agama Hindu, Vol 4, No. 2, 2022

ISSN: 2656-7466

Data yang sudah tersusun dalam pola atau grafik tertentu kemudian disimpulkan sehingga makna data bisa ditemukan. Dan simpulan ini baru bersifat sementara dan umum. Agar lebih mendalam perlu data baru sebagai pembanding atau pengujian terhadap simpulan yang diambil, sehingga kebenaran simpulan jauh lebih akurat.

\section{HASIL DAN PEMBAHASAN}

1. Asal-Usul Sampi Gerumbungan Desa Kaliasem

Berkembangnya seni budaya Sampi Gerumbungan di desa Kaliasem, Kabupaten Buleleng diperkirakan dimulai sekitar tahun 1923. Terciptanya seni budaya Sampi Gerumbungan ini merupakan hasil kreativitas para petani di desa Kaliasem. Sudah diketahui bersama bahwa saat para petani membajak sawahnya umumnya menggunakan bajak yang disebut tenggala/lampit ditarik oleh dua ekor sapi. Proses membajak ini disebut dengan metekap/nglampit. Kegiatan metekap atau nglampit inilah yang menginfirasi para petani untuk menciptakan sebuah kesenian yang terkait dengan pekerjaan atau profesinya sehari-hari sebagai petani. Dari kegiatan metekap atau nglampit ini dikemas sedemikian rupa dan ditambah dengan kreasi-kreasi baru untuk menambah keindahan, maka terciptalah seni budaya Sampi Gerumbungan ini. Dan seni budaya ini umumnya dipentaskan setelah mereka berhasil dalam pertaniannya.

Pada awalnya seni budaya Sampi Gerumbungan ini hanya terkait dengan bidang pertanian, karena dipentaskan untuk kepentingan para petani. Artinya, diciptakan, dilakoni dan dinimati oleh petani setelah mereka menikmati hasil kerja mereka di sawah. Sebagai rasa syukur kepada Hyang Widhi Wasa, maka mereka membuat sebuah permainan atau sebuah kesenian yang dapat menghibur di kalangan para petani itu sendiri.

Kita ketahui bahwa desa Kaliasem, tempat terciptanya Seni Budaya Sampi Gerumbungan ini adalah termasuk wilayah berkembangnya pariwisata di Kabupaten Buleleng. Mengingat seni budaya Sampi Gerumbungan, sebuah atraksi yang cukup menarik bukan saja bagi kalangan petani, melainkan juga bagi masyarakat umum dan parawisatawan baik yang berasal dari dalam negeri maupun manca negara, maka sejak tahun 1986 keberadaan Sampi Gerumbungan ini mulai dimanfaat dalam dunia parisata di Buleleng untuk menarik datangnya para wisatawan ke Buleleng. Oleh karena itu, sejak tahun 1986 keberadaan Sampi Gerumbungan tidak saja terkait dengan dunia pertanian, melainkan sudah merambah pada bidang pariwisata.

\section{Nilai-nilai yang Terkandung dalam Seni Budaya Sampi Gerumbungan.}

Nilai-nilai yang dimaksud dalam hal ini adalah segala sesuatu atau hal-hal yang penting bagi kemanusiaan (KKBI, 1994:690), yakni hal-hal yang penting yang dapat dipetik dari keberadaan seni budaya Sampi Gerumbungan, antara lain:

a. Nilai Keindahan;

Keindahan yang dimaksud dalam hal ini adalah hal-hal yang mengandung unsur seni, unsur halus, bagus, elok, kebenaran dan lain-lain yang dapat menimbulkan kepuasan, kenikmatan, bagi yang melihat atau yang menikmati. Dalam pementasan Sampi Gerumbungan di desa Kaliasem semua hal tersebut akan didapatkan, karena dalam pementasan Sampi Gerumbungan ini menampilkan gerakan-gerakan dari sapi dan pengatiknya yang mengagumkan, seperti langkah kaki sapi yang serempak antara kaki-kaki kedua sapi sehingga nampak gerakan kakinya seperti gerak kaki peserta gerak jalan, sapi-sapi menggunakan peralatan dan kostum yang serba dihiyas dengan seindah mungkin sehingga tidak membosankan bagi yang 
melihat atau penontonnya seperti leher sapi digantungkan keroncongan yang berukuran besar yang disebut Gerumbungan, sedangkan di kakinya dipasangkan gongseng. Gerumbungan dan gongseng akan menghasilkan bunyi-bunyi atau suara dengan alunan suara yang berbeda akan menambah kesemarakan pementasan Sampi Gerumbungan tersebut.

b. Nilai Budaya;

Sampi Gerumbungan adalah hasil kreasi atau olah fikir dari para petani setelah mereka memetik hasil panennya. Hasil olah fikir ini mereka lakukan sebagai rasa syukur kepada Hyang Widhi Wasa, Tuhan Yang Maha Esa. Jadi keberadaan Sampi Gerumbungan ini atas hasil daya dan budhi manusia, dalam hal ini para petani. Oleh karena itu, keberadaan dan pementasan Sampi Gerumbungan tentu mengandung nilai budaya, karena dilihat dari terciptanya seni budaya ini atas dasar hasil kreasi dan olah fikir para petani. Walaupun pada mulanya dilakukan dengan sederhana saat membajak sawah, yang dikenal dengan metekap, tidak dilengkapi dengan berbagai perhiyasan seperti pementasan Sampi Gerumbungan dewasa ini. Yang jelas terciptanya Sampi Gerumbungan ini mengandung nilai budaya yang bernilai tinggi.

c. Nilai Sakral;

Budaya masyarakat Hindu di Bali setiap apapun aktivitas yang dilaksanakan selalu diawali dengan pemilihan hari baik, dewasa ayu dan pada hari baik itu mengawali kegiatan yang dimaksud dengan pelaksanaan ritual keagamaan, seperti mengawali belajar menari, membangun rumah, menanam padi di sawah, mengawali usaha berdagang dan lain-lain selalu diawali dengan upacara yang disertai dengan sesaji berupa banten/upakara. Demikian pula dalam pementasan Sampi Gerumbungan ini. Pemetasan budaya Sampi Gerumbungan ini diawali dengan upacara yadnya, yakni korban suci yang dipersembahkan kepada Hyang Widhi Wasa, Tuhan Yang Maha Esa dengan mempersenbahkan berbagai jenis sesaji, berupa beberapa jenis banten antara lain banten teteg Daksina, tipat gong, nasi sebelar warna dan lain-lain sebagai bentuk persembahan sekaligus permohonan kepada Tuhan agar pelaksanaan pementasan Sampi Gerumbungan itu dapat berjalan dengan lancar tanpa ada halangan atau rintangan atau berhasil dengan baik.

d. Nilai Ekonomis;

Dewasa ini pementasan Sampi Gerumbungan ini tidak lagi hanya pada saat akhir panen raya dari para petani, melainkan sudah merambah pada sektor pariwisata, yakni dipentaskan untuk para wisatawan yang berkunjung ke bumi Panji Sakti. Bahkan pementasan Sampi Gerumbungan dewasa ini justru terkait dengan parawisata inilah yang lebih dominan. Dengan dipentaskan dalam bidang parawisata berdampak positif baik dilihat dari keajegan keberadaan seni budaya Sampi Gerumbungan itu sendiri maupun berkembangnya parawisata di Buleleng. Dengan dipentaskan dan dilombakan seni budaya Sampi Gerumbungan ini mendorong berdirinya kelompok-kelompok Sampi Gerumbungan di Buleleng. Dewasa ini sudah terbentuk kelompok-kelompok Sampi Gerumbungan di masing-masing Kecamatan di Kabupaten Buleleng. Dan kelompok-kelompok inilah yang akan menjadi peserta pertandingan yang biasanya dilaksanakan oleh pemerintah Buleleng untuk menyambut dan merayakan hari kemerdekaan Republik Indonesia sekaligus dijadikan salah satu paket wisata oleh pemerintah daerah.........

3. Peralatan yang Digunakan dalam Pementasan Sampi Gerumbungan.

Ada beberapa peralatan yang digunakan dalam atraksi Sampi Gerumbungan, yaitu:

e. Uga; 
Jurnal Widya Sastra Pendidikan Agama Hindu, Vol 4, No. 2, 2022

ISSN: 2656-7466

Uga adalah sebuah alat yang terbuat dari kayu untuk mengikat dua ekor sapi untuk membajak sawah. Uga ini dibentuk sedemikian rupa, yang diletakan di kedua leher sapi, dan di tengah-tengahnya disambungkan dengan tenggala atau lampit sebagai sarana untuk menggemburkan atau meratakan tanah

f. Sambed;

Sambed adalah alat untuk memingat leher sapi dengan uga, terbuat dari rotan yang dianyam sedemikian rupa dan ada pula yang dibuat dari karet ban bekas.

g. Kunali;

Kunali adalah tali untuk mengikat antara uga dengan lampit, dibuat dari kulit pelapah kelapa setengah tua, dan biasanya didobelkan agar kuat dan dapat menarik beban lampit/tenggala beserta pengatiknya/jokinya.

h. Lampit;

Lampit adalah alat yang ditarik sapi, yang terbuat dari kayu berfungsi untuk meratakan tanah sekaligus sebagai tempat duduk pengatik atau joki.

i. Tali Tengen;

Tali tengen adalah tali yang terbuat dari ijuk atau bambu (tali tiing) yang dililitkan untuk menuntuk kedua sampi gerumbungan.

j. Kaun Lampit;

Kaun Lampit adalah alat untuk menjaga keseimbangan joki dan meratakan tanah terbuat dari kayu atau papan.

k. Pelayah;

Pelayah terbuat dari bambu yang berfungsi untuk memperingan beban tarikan sapi.

I. Gelang Gongseng;

Gelang Gongseng dibuat dari kuningan atau tembaga yang diikatkan pada kedua kaki sapi bagian depan berfungsi untuk memperindah penampilan sampi gerumbungan sekaligus gelang gongseng ini dapat mengeluarkan suara yang nyaring yang menandakan kesepakan langkahnya sapi.

m. Gerumbungan;

Gerumbungan disebut pula keroncongan. Antara Gerumbungan dengan keroncongan hanya berbeda ukurannya saja. Yang disebut Gerumbungan adalah keroncongan yang ukurannya besar. Alat ini biasanya terbuat dari kayu intaran atau kayu temali yang dibentuk sedemikian rupa digantungkan di leher sapi berfungsi untuk menambah keindahan dan juga menambah kesemarakan dari bunyi yang dihasilkan Gerumbungan tersebut.

n. Pecut;

Pecut atau cambuk terbuat dari rotan untuk mencambuk badan sapi apabila para joki ingin mempercepat jalannya sapi.

o. Pengatik;

Yang disebut dengan Pengatik adalah joki atau kusir yang mengendalikan jalannya Sampi Gerumbungan tersebut.

4. Keberadaan Sampi Gerumbungan dalam Kaitannya dengan Pariwisata di Kabupaten Buleleng.

Dengan dimanfaatkannya Sampi Gerumbungan itu dalam bidang pariwisata berdampak pada keberadaan Sampi Gerumbungan itu sendiri. Warna dan bentuk Sampi Gerumbungan yang hidup dan berkembang dewasa ini sudah jauh berbeda dengan warna Sampi Gerumbungan pada saat awalnya diciptakan oleh para petani. Ada berbagai perubahan yang terjadi dalam pelaksanaan atau pementasan Sampi Gerumbungan antara lain: 
Jurnal Widya Sastra Pendidikan Agama Hindu, Vol 4, No. 2, 2022

ISSN: 2656-7466

\section{a. Tempat Pelaksanaan;}

Pada awalnya tempat yang digunakan di sawah petani masing-masing, atau di areal sawah yang berair, tanah yang becek, sehingga setelah pelaksanaan Sampi Gerumbungan ini, biasa baik sapi maupun pengatiknya, penuh dengan lumpur. Namun dewasa ini karena ditampilkan bagi para wisatawan, maka tempatnya dipindahkan dari tanah berlumpur ke tanah kering, yaitu di lapangan yang ada di desa Kaliasem. Hal ini dilakukan agar dapat dinikmati oleh para wisatawan lebih mudah, lebih bersih, lebih menarik karena tujuannya memang untuk memberikan hiburan bagi penonton atau wisatawan.

b. Waktu Pelaksanaan;

Dilihat dari segi waktu pementasan juga mengalami perubahan, yang pada mulanya selalu dikaitkan dengan masa panen, sebagai bentuk rasa syukur dari petani tetapi sekarang karena terkait dengan pariwisata, maka pementasan Sampi Gerumbungan ini dikaitkan dengan even-even pariwisata dan perayaan-perayaan hari-hari nasional, seperti merayakan hari kemerdekaan Indonesia.

c. Kostum yang Digunakan;

Kostum yang digunakan baik untuk sapi maupun pengatiknya sudah jauh berbeda dengan awal-awal Sampi Gerumbungan ini diciptakan. Dahulu kedua sapi yang digunakan dalam Sampi Gerumbungan ini dihiyasi dengan alat-alat apa adanya sebagai mana alat yang digunakan pada saat mereka bekerja membajak sawah sehari-hari. Demikian pula joki/pengatiknya mereka menggunakan pakaian kerja sehari-hari; menggunakan celana pendek/ sarung, baju kaos dan topi bahkan bisa tak pakai baju. Namun karena pementasan sekarang terkait dengan lomba, tontonan untuk para wisatawan, maka bentuk penampilan menjadi perhatian khusus. Ini yang menyebabkan kostum yang dikenakan baik bagi sapi maupun pengatiknya ditingkatkan kualitas keindahannya. Alat-alat yang digunakan untk sapi seperti gongseng, Gerumbungan/keroncongan dan lain-lain dihiyas dengan berbagai warna agar lebih semarak dan lebih menarik; joki atau pengatiknya menggunakan pakaian yang lengkap seperti udeng, kemen, saput bahkan menggunakan mik up wajah seperti dandanan para pecalang. Hal ini dilakukan agar lebih indah dipandang mata dan lebih menarik.

\section{d. Kreteria Penilaian;}

Mengingat keberadaan Sampi Gerumbungan sekarang ini dilombakan, maka ada kreteria penilaian yang diberlakukan atas lomba tersebut. Di sinilah letak perbedaan Sampi Gerumbungan dengan seni budaya yang sejenis seperti Karapan Sapi di Madura dan Makepung, di Jembrana. Kedua atraksi loba ini penilaiannya hanya didasarkan pada kecepatan larinya saja, kurang mempertimbangkan unsur keindahan; sedangkan Sampi Gerumbungan di samping kecepatan juga yang dinilai : a. ketepatan arah sapi sesuai dengan jalur yang telah ditentukan, b. langkah kedua sapi harus bersamaan, c. kepala sapi harus mendongok ke atas saat lomba, dan d. Gerumbungan atau keroncongan dan gongseng harus berbunyi mengalun yang serasi dengan langkah sapi.

e. Penikmat Sampi Gerumbungan;

Dahulu yang menjadi penikmat atau penonton dari Sampi Gerumbungan ini hanyalah dari kalangan petani di lingkungan Subak yang bersangkutan. Semenjak dijadikan salah satu agen untuk dapat menarik para wisatawan terutama wisatawan manca negara tentu yang menikmati pementasan Sampi Gerumbungan ini mengalami perluasan dari para petani menjadi masyarakat umum bahkan menyakut masyarakat dunia. Jadi dewasa ini yang dapat menikmati dari pelaksanaan atau pementasan Sampi Gerumbungan ini siapa saja tidak dibatasi dari satu profesi seperti dahulu, 
Jurnal Widya Sastra Pendidikan Agama Hindu, Vol 4, No. 2, 2022

ISSN: 2656-7466

melainkan dari berbagai profesi, dari berbagai desa, dari berbagai pulau bahkan dari para touris dari berbagai benua atau negara.

\section{KESIMPULAN \& SARAN}

Berdasarkan uraian di atas berikut ini akan disajikan simpulan dan berdasarkan simpulan tersebut disampai beberapa saran sebagai berikut.

Simpulan

a. Asal-usul berkembangnya seni budaya Sampi Gerumbungan di desa Kaliasem diperkirakan dimulai dari tahun 1923. Sampi Gerumbungan ini tercipta dari hasil kreativitas para petani setelah mereka panen raya dan mengawali membajak tanah (metekap). Pada awalnya dilaksanakan apa adanya. Artinya peralatan yang digunakan hanya terbatas pada peralatan yang mereka gunakan seperti mereka membajak tanah biasa. Dan dalam perkembangan berikutnya pementasan Sampi Gerumbungan ini tidak saja terkait dengan pertanian melainkan berimbas pula pada bidang parawisata, karena dimanfaatkan oleh pemerintah Buleleng sebagai salah satu paket wisata di Buleleng, sehingga sampai saat ini ada kelompok-kelompok Sampi Gerumungan di Buleleng. Dan peralatan dan atribut yang digunakan baik pada sapi maupun pengatiknya sudah dihiyas sedemikian rupa sehingga tampak jauh lebih indah dan menarik.

b. Ada berbagai nilai yang terkandung dalam seni budaya Sampi Gerumbungan, antara lain: a. nilia seni/keindahan, b. nilai budaya, c. nilai sacral dan d. nilai ekonomis.

c. Peralatan yang digunakan dalam Sampi Gerumbungan, antara lain: a. Uga; b. Samped, c. Kunali, d. Lampit, e. Tali Tengen, f. daun lampit, g. pelayah, h. Gelang Gongseng, i. Gerumbungan, j. Pecut dan k. Pengatik.

d. Keberadaan sampi Gerumbungan dewasa ini sudah mengalami perubahan dilihat dari tempat pelaksanaannya, waktu pelaksanaannya, Kostum yang digunakan pada saat pementasan, kreteria pementasan dan para penikmat atau penoton pertunjukan Sampi Gerumbungan tersebut. Semua ini mengalami peningkatan kualitasnya.

Saran

a. Para petani sangat berjasa dengan terciptanya sebuah seni budaya Sampi Gerumbungan ini, karena itu disarankan para petani yang sekarang ini diharapkan tetap berkreativitas agar nantinya diharapkan terciptanya seni budaya-seni budaya yang lain sehingga dapat menambah dan meningkatkan seni budaya Buleleng.

b. Mengingat keberadaan Sampi Gerumbungan dewasa ini tidak saja terkait dengan pertanian yang pada mulanya hanya sebagai hiburan dalam komunitas petani, melainkan sudah merambah dunia pariwisata, menjadi salah satu paket wisata sehingga keberadaannya sudah menjadi salah sumber pemasukan pemerintah daerah dan masyarakat, karena itu disarankan agar disisihkan masukan ini untuk pembinaan dan peningkatan kualitas Sampi Gerumbungan ini.

c. Mengingat keberadaan Sampi Gerumbungan ini dilombakan diharapkan kedepan dibuatkan kreteria-kreteria penilaian yang jelas yang dapat diketahui baik oleh kelompok yang bertanding maupun masyarakat penontonnya. 
Jurnal Widya Sastra Pendidikan Agama Hindu, Vol 4, No. 2, 2022

ISSN: 2656-7466

\section{DAFTAR PUSTAKA}

Agus Salim, (Penyunting) (2001). Teori dan Paradigma Penelitian Sosial (dari Denzin Guba dan Penerapannya), Penerbit: PT. Tiara Wacana Yogyakarta.

Alwasilah, A. Chaedar (2002). Pokoknya Kualitatif, Dasar-dasar Merancang dan Melakukan Penelitian Kualitatif, Penerbit: Pt Dunia Pustaka Jaya dan Pusat Studi Sunda, Jakarta.

Bakker, Dr. Anton \& Drs. Achmad Charris Zubair (1994) Metodelogi Penelitian Filsafat, Penerbit: Kanisius, Yogyakarta.

Bryan \& Jurner (2006). Agama \& Teori Sosial, Penerbit: IRCiSod, Yogyakarta.

Drama Putra, I Nyoman (Editor). (2004). Bali Menuju Jagadhita: Aneka Perspektif, Penerbit: Pustaka Balipost, Denpasar.

Dasim Mathar, MA. DR. H. Moch. (2005). Sejarah, Teologi dan Etika, Agama-agama. Penerbit: Dian/Interfidei, Yogyakarta.

Gunadha, M.Si, Prof. Dr. Ida Bagus (2008-2009), Pemberdayaan Desa Pakraman, Sebagai Strategi Kebertahanan Adat, Budaya dan Agama Hindu Bali. Pembinaan Desa Pekraman, Kerja sama UNHI Denpasar \& Kanwil Departemen Agama Propinsi Bali.

Kutha Ratna, SU. Prof. Dr. Nyoman (2010) Metodelogi Penelitian Kajian Budaya dan Ilmu Sosial Humaniora pada Umumnya, Penerbit: Pustaka Pelajar, Yogyakarta.

Nyoka (1990) Sejarah Bali, Penerbit: Toko Buku Ria, Denpasar.

Singgin Wikarman, Drs. I Nyoman, (1998). Sanggah Kamulan, Fungsi dan Pengertiannya, Penerbit: Paramita, Surabaya.

Simpen, AB. Wayan (1986). Adat Kuna, Catur Desa (Tiga Wasa, Sidatapa, Pedawa, Cempaga). Penerbit: -

Soebandi, Ktut (2008). Riwayat Merajan di Bali, Penerbit: CV. Kayumas Agung, Denpasar.

Soebandi, Ktut (1981). Pura Kawitan/Padharman dan Panyungsungan Jagat, Penerbit: CV. Kayumas, Denpasar.

Soebandi, Ktut (1983). Sejarah Pembangunan Pura-pura di Bali, Penerbit: CV. Kayumas, Denpasar.

Suasthawa Dharmayuda, SH. I Made (1995). Kebudayaan Bali, Pra Hindu, Masa Hindu dan Pasca Hindu, Penerbit: CV. Kayumas Agung, Denpasar.

Sudarsana,MBA.MM. Drs. I.B.Putu (2000). Ajaran Agama Hindu Manifestasi Sang Hyang Widhi, Penerbit: Yayasan Dharma Acarya, Percetakan Mandara sastra, Denpasar.

Sugeng Pujilaksono. (2006). Petualangan Antropologi, Sebuah Pengantar IImu Antropologi, Pnerbit: UPT. Penerbitan Universitas Muhammadiyah, Malang.

Sutaba, I Made (1980) Prasejarah Bali, Penerbit: B.U Yayasan Purbakala Bali.

Tantera Keramas, Prof. Dr. Dewa Made (2008) Metode Penelitian Kwalitatif dalam IImu Agama dan Kebudayaan; Penerbit: Paramita, Surabaya.

Team Penyusun, (1993). Pedoman Pembinaan Umat Hindu Dharma Indonesia, Penerbit: Upada Sastra, Denpasar.

Team Penyusun, (1985/1986). Sejarah Perkembangan Agama Hindu di Bali, Penerbit: Proyek Penyuluhan Agama dan Penerbitan Buku Agama (1985/1986), Pemerintah Daerah Tingkat I Bali, Denpasar.

Tim Penyusun, (2005). Pedoman Pembinaan Lembaga Keagamaan Hindu, Penerbit: Paramita, Surabaya.

Triguna, Ida Bagus Gede Yudha, (2001). Mengapa Bali Unik; Penerbit: Pustaka Jurnal Keluarga, Jakarta.

(2001). Strategi Hindu; Penerbit: Pustaka Jurnal Keluarga, Jakarta. 
Jurnal Widya Sastra Pendidikan Agama Hindu, Vol 4, No. 2, 2022

ISSN: 2656-7466

Pendit, Nyoman S. (1995). Hindu Dalam Tafsir Modern, Penerbit : Yayasan Dharma Naradha, Denpasar.

Purwita, Drs. Ida bagus Putu, (1984). Desa Adat dan Banjar di Bali, Penerbit: Percetakan Kawi Sastra, Denpasar. 